\title{
Knowledge and Practice on Prevention of Respiratory Health Problems among Traffic Police in Kathmandu, Nepal
}

\author{
Ambika Aryal Bhandari, ${ }^{1}$ Roshani Gautam, ${ }^{1}$ and Shiva Bhandari ${ }^{2,3}$ \\ ${ }^{1}$ Maharajgunj Nursing Campus, Institute of Medicine, Tribhuvan University, Maharajgunj, Kathmandu 44616, Nepal \\ ${ }^{2}$ Central Department of Microbiology, Tribhuvan University, Kirtipur, Kathmandu 44613, Nepal \\ ${ }^{3}$ Kantipur College of Medical Science, Tribhuvan University, Sitapaila, Kathmandu 44600, Nepal \\ Correspondence should be addressed to Ambika Aryal Bhandari; arambik185@gmail.com
}

Received 27 May 2015; Revised 23 July 2015; Accepted 26 July 2015

Academic Editor: Longyi Shao

Copyright (c) 2015 Ambika Aryal Bhandari et al. This is an open access article distributed under the Creative Commons Attribution License, which permits unrestricted use, distribution, and reproduction in any medium, provided the original work is properly cited.

\begin{abstract}
Introduction. Traffic police in Kathmandu are continuously exposed to air pollution and are at an increased health risk. This study aimed to assess the knowledge and practice regarding prevention of respiratory problems among traffic police in Kathmandu. Methods. A descriptive exploratory study was conducted among the traffic police $(n=83)$ working in six areas of the Kathmandu Metropolis from July to August 2013. Self-administered questionnaires were distributed to all the participants. Results. The mean age $( \pm \mathrm{SD})$ of the respondents was $28.8 \pm 4.3$ years. More than half of the respondents had 6-10 years of work experience, the mean $( \pm \mathrm{SD})$ years of experience being $7.9( \pm 3.6)$. The level of knowledge regarding the prevention of respiratory problems was better than the level of practice among the respondents. Education of the participants did not affect the level of practice of the respondents while there was association between working experience and level of practice $(p=0.04)$. Conclusion. Since the preventive practice is poor, the government should come up with plans such as distribution of antipollution masks to improve the level of practice among traffic police to prevent respiratory problems.
\end{abstract}

\section{Introduction}

Occupational health risks and hazards due to polluted environment have become a serious public health concern where there is unplanned urbanization. Pollution due to road traffic is a serious health hazard and thus the persons like traffic police who are continuously exposed may be at an increased risk $[1,2]$. The traffic police have to undergo physical strain in an environment polluted by fumes, exhaust of vehicles, use of blowing horns, emission from nearby brick factories, and blow of dust in the air by a speeding vehicle.

The traffic situation in Kathmandu Metropolis is dominated by an enormous increase of motorized vehicles. Altogether 688,026 vehicles have been added to the Bagmati zone from 1990 to 2013 and most of them are being added to the already congested roads of the Kathmandu Valley [3]. Of the total vehicles, only $2.7 \%$ of vehicles are public while $92.1 \%$ of vehicles are privately owned [4]. According to a report from Clean Air Network Nepal, motorcycles dominate the vehicles composition by $73.2 \%$ and Car/Jeep/Van by $18.5 \%$ [5].
A study shows that vehicle flow in Kathmandu is TwoWheelers (motorcycles) (77.5\%), Taxi (8.2\%), Car/Jeep/Van (7.6\%), Truck/Mini Truck (1.9\%), Bus/Minibus (1.7\%), and Microbus (1.6\%) [6].

Air pollution from vehicles is the complex function of fuel characteristics, extents of combustion, reactions with other gases, and atmospheric condition. The major fuels used in vehicles of Nepal are diesel and petrol. However, adulteration (mainly with kerosene) in such fuels can increase ambient air pollution. A study in Nepal showed that existing diesel (commercially dispensed at automotive fuel pump stations) indicated presence of $30-50 \%$ kerosene in diesel [7].

In Nepal, air quality crisis in cities is mainly due to increased vehicular emission, rampant construction works, and unmanaged factories $[8,9]$. The World Health Organization (WHO) has found Kathmandu as one of the most polluted cities in Asia with regard to $\mathrm{PM}_{10}$ (particulate matter) and $\mathrm{PM}_{2.5}$ level in ambient air [10]. Adverse health effects due to air pollution range anywhere from minor 
irritation of eyes and the upper respiratory system to chronic respiratory disease, heart disease, lung cancer, and death [11]. The particles emitted from the vehicular exhaust of more than 10-micron size are held in upper respiratory tract and particles less than 10-micron size accumulate in the lung and produce respiratory abnormalities [12].

According to the WHO, outdoor air pollution caused about 3.7 million premature deaths worldwide in 2012, 88\% of those occurring in low- and middle-income countries [11]. A study conducted in 2006 in Nepal revealed a fact that over 1,900 premature deaths occur per year in Kathmandu Valley due to air pollution [13]. According to the Metropolitan Traffic Police Office in Singha Durbar, as many as 50 traffic police personnel fall ill daily due to hazardous dust on the recently demolished but yet-to-be-reconstructed roads (unpublished data). Similarly, a study showed that the negative effect of air pollution on health of dwellers in Kathmandu Valley is extreme [14]. Therefore, this study aimed to assess the knowledge regarding respiratory problems among traffic police in Kathmandu Valley and common preventive measures adopted by them to prevent respiratory problems.

\section{Methods}

2.1. Study Design and Setting. A descriptive exploratory research was conducted among the traffic police working in six areas of Kathmandu city from July to August 2013. The selected areas were Singha Durbar, Maharajgunj, Kalanki, Koteshwor, Gaushala, and Kalimati. These areas were selected randomly with the guidance from the Ramshah Path, Kathmandu, Metropolitan Traffic Police Division. The study sites are shown in Figure 1.

2.2. Sampling and Sample Size. Simple random sampling technique was used in the study. The list of all traffic police from each area was obtained from Metropolitan Traffic Police Division, Ramshah Path, Kathmandu. The sample was selected as whoever was available in the selected area to fulfill the criteria of the study. Therefore, a total of 83 samples were taken for the study. However, those traffic police who were involved in administrative work and had less than 6 months of work experience were excluded from the study.

\subsection{Questionnaires and Data Collection Procedure. Close} ended/open ended structured questionnaires were developed which included information regarding demography, knowledge, and practice on prevention of respiratory problems. All the questionnaires were translated into Nepali language for the ease of respondents (traffic police) to answer the questions. The content of the questionnaire was developed by an extensive consultation with the public health experts and Metropolitan Traffic Police Division, Ramshah Path, Kathmandu. The internal consistency of the questionnaires was obtained with Cronbach's alpha score of 0.83 for knowledge and 0.6 for practice.

Pretesting of the questionnaires was done with respondents at Kamalpokhari branch, Kathmandu. A total of nine

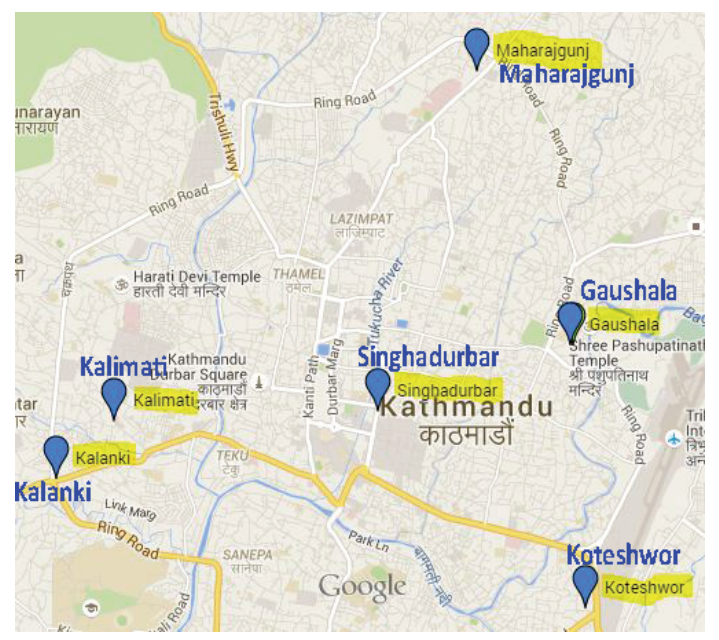

Figure 1: Map of study areas in Kathmandu Metropolis, Nepal.

traffic police officers were enrolled in the pilot study. After taking their feedback, seven out of the nine traffic police officers mentioned "use of antipollution mask" to protect from air pollution in knowledge-related questions. This was added in the final study. Similarly, information regarding "rotation in duty area" was added in the final study as five out of nine traffic police officers mentioned it. However, these pretest respondents were not included in actual study.

Self-administered questionnaires in Nepali language were distributed to all the study respondents. The respondents were briefed on the purpose of the study beforehand and they were briefed on the details of the questionnaires. Fifteen to thirty minutes was allotted for each subject for filling the questionnaires. The respondents filled the questionnaire in the presence of the researcher and the questionnaire was immediately collected.

2.4. Ethical Consideration. Ethical approval was taken from research committee of Nursing Campus, Maharajgunj. Similarly, permission was obtained from the Metropolitan Traffic Police Division, Ramshah Path, Kathmandu. Verbal and written informed consent was taken from each respondent before collecting data. Anonymity and confidentiality was maintained through the study and none was compelled to participate in the study.

2.5. Ranking of the Respondents. In the evaluation of level of knowledge of the respondents, 14 knowledge-related questions were included. Every right answer was awarded one mark and every wrong answer was awarded zero. In addition, multiple choice answer was awarded more than one mark for each correct answer. The total score of knowledge-related questions was 36. Similarly, in the evaluation of level of practice of the respondents, a total of five questions regarding the preventive practice for respiratory problems were included. The total score was five. The ranking of respondents was done as follows: below average (score $<50 \%$ ), average (score of $50 \%$ to $69 \%$ ), and above average (score $\geq 70 \%$ ). 
TABLE 1: Biodemographic characteristics of the respondents $(n=$ $83)$

\begin{tabular}{|c|c|c|}
\hline Variables & Frequency & Percent \\
\hline \multicolumn{3}{|l|}{ Age (in years) } \\
\hline $20-24$ & 10 & 12.0 \\
\hline $25-29$ & 40 & 48.2 \\
\hline $30-34$ & 21 & 25.3 \\
\hline $35-40$ & 12 & 14.5 \\
\hline \multicolumn{3}{|c|}{ Mean $( \pm$ SD $)=28.8 \pm 4.3$} \\
\hline \multicolumn{3}{|c|}{ Sex } \\
\hline Male & 78 & 94.0 \\
\hline Female & 5 & 6.0 \\
\hline \multicolumn{3}{|l|}{ Marital status } \\
\hline Married & 66 & 79.5 \\
\hline Unmarried & 16 & 19.3 \\
\hline Separated & 1 & 1.2 \\
\hline \multicolumn{3}{|l|}{ Education } \\
\hline SLC & 28 & 33.7 \\
\hline Intermediate level & 41 & 49.4 \\
\hline Bachelor's degree & 10 & 12.0 \\
\hline Master's degree & 4 & 4.8 \\
\hline \multicolumn{3}{|l|}{ Experience (in years) } \\
\hline $1-5$ & 18 & 21.7 \\
\hline $6-10$ & 46 & 55.4 \\
\hline $11-15$ & 17 & 20.5 \\
\hline $16-20$ & 2 & 2.4 \\
\hline
\end{tabular}

2.6. Data Processing and Management. Initially, the collected data was checked daily for its completeness. The data was entered to and analyzed in Statistical Package for Social Sciences (SPSS Inc., version 18). Descriptive statistics were made by using proportions, mean, and standard deviation (SD), while inferential calculation was made using Fischer's exact test. $P$ value $<0.05$ was considered significant.

\section{Results}

The mean age $( \pm \mathrm{SD})$ of the respondents was $28.8 \pm 4.3$ years. Majority of the respondents $(94.0 \%, n=78)$ were male and nearly four-fifth of the respondents $(79.0 \%, n=66)$ were married. Regarding educational status, all the respondents had completed SLC (School Leaving Certificate) and almost half of them had passed intermediate level. More than half of the respondents had 6-10 years of work experience, the mean $( \pm$ SD) years of experience being $7.9( \pm 3.6)$ (Table 1$)$.

Among the effects of the pollution on respiratory system, the majority $(84.3 \%, n=70)$ responded with lung cancer followed by bronchial asthma $(78.3 \%, n=65)$. More than ninety percent $(n=75)$ responded with difficulty in breathing as a major sign and symptom when they get respiratory problems. Similarly, among the ways, nearly fourfifth reported that the use of mask and about three-fifth reported that regular health checkup can prevent the effects of
TABLE 2: Knowledge regarding respiratory problems due to air pollution and their prevention.

\begin{tabular}{lcc}
\hline Variables & Frequency & Percent \\
\hline Effects on respiratory system & 36 & \\
Pneumonia & 70 & 83.4 \\
Lung cancer & 65 & 78.3 \\
Bronchial asthma & 59 & 71.1 \\
Common cold & & \\
Sign and symptoms of respiratory problems & 48 & 57.8 \\
Cough & 75 & 90.4 \\
Difficulty in breathing & 59 & 71.1 \\
Wheezing sound & 44 & 53.0 \\
$\quad$ Sneezing and running nose & & \\
Preventive measures to avoid respiratory & & \\
problems & 55 & 66.3 \\
Proper management of waste & 65 & 78.3 \\
Wearing mask & 48 & 57.8 \\
Regular health checkup & 49 & 59.0 \\
Less work on polluted area & & \\
Suitable mask to protect from air pollution & 14 & 16.9 \\
Cloth mask & 62 & 74.7 \\
Antipollution mask & 7 & 8.4 \\
Gas mask & & \\
\hline
\end{tabular}

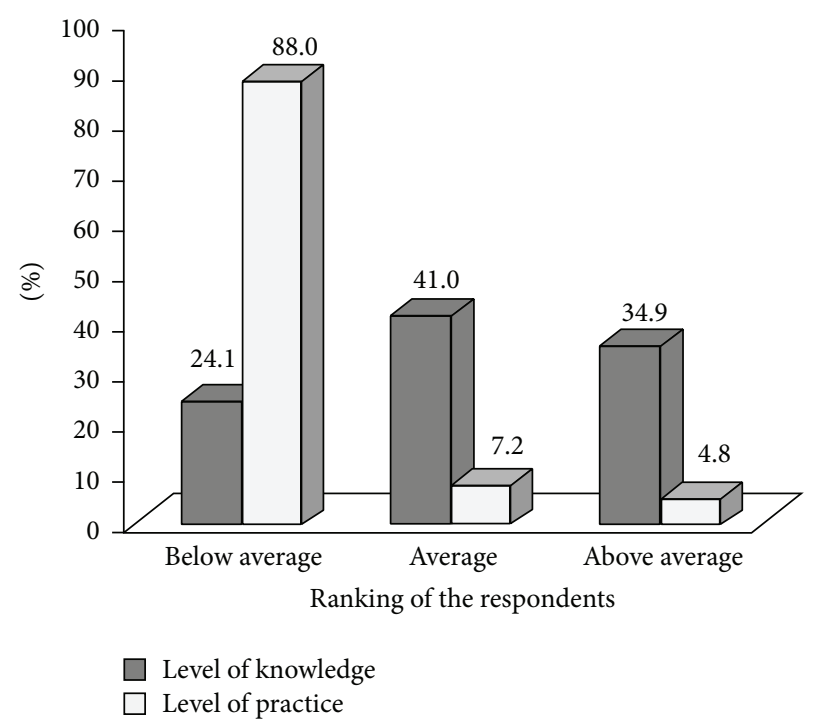

FIGURE 2: Level of knowledge and practice on prevention of respiratory problems.

air pollution. About three-fourth reported that antipollution mask was a suitable mask to prevent air pollution (Table 2).

$88.0 \%(n=73)$ of the respondents had below-average level of practice to prevent respiratory problems. Likewise, $41.0 \%(n=34)$ of the respondents had average level of knowledge regarding the prevention of respiratory problems (Figure 2). 
TABLE 3: Practice on prevention of respiratory problems.

\begin{tabular}{lcc}
\hline Variables & Frequency & Percent \\
\hline Use of masks & 78 & 94.0 \\
Decreased duty hours & 10 & 12.0 \\
Rotation in duty area & 46 & 55.4 \\
Regular checkup & 8 & 9.6 \\
Implement rules in vehicles regarding air & 5 & 6.0 \\
pollution & & \\
\hline
\end{tabular}

TABle 4: Association of education with level of practice on prevention of respiratory problems.

\begin{tabular}{lcccc}
\hline \multirow{2}{*}{ Education } & \multicolumn{4}{c}{ Level of practice } \\
& I (\%) & II (\%) & III (\%) & $P$ value \\
\hline SLC $(n=28)$ & $25(89.3)$ & $2(7.1)$ & $1(3.6)$ & \\
Intermediate $(n=41)$ & $37(90.2)$ & $2(4.9)$ & $2(4.9)$ & 0.32 \\
Bachelor's degree $(n=10)$ & $8(80.0)$ & $2(20.0)$ & $0(0.0)$ & \\
Master's degree $(n=4)$ & $3(75.0)$ & $0(0.0)$ & $1(25.0)$ & \\
\hline
\end{tabular}

Note. I: below average; II: average; III: above average.

The majority of the respondents $(94.0 \%, n=78)$ used masks during duty hours while more than half of the respondents had rotation in duty areas in order to prevent respiratory problems. Less than one out of 10 respondents had regular health checkup (Table 3 ).

The level of practice was below average (I) in majority of respondents having intermediate level of education. In addition, there was no association between education and level of practice (Table 4).

The majority of respondents with 11 to 15 years of working experience had level of knowledge above average followed by respondents with 16 to 20 years of experience. $91.3 \%(n=43)$ of respondents with experience of 6 to 10 years had level of practice below average. There was an association between working experience and level of practice $(P=0.04)$ (Table 5).

\section{Discussion}

The present study showed that the traffic police had knowledge regarding the negative effects of air pollution on their health. They had knowledge that air pollution can cause difficulty in breathing, wheezing sound, lung cancer, bronchial asthma, and pneumonia. Studies conducted in India have also found that there is increased risk of getting different respiratory problems when traffic police are exposed to polluted air for a longer time $[2,15]$. It is essential for traffic police to be aware of the problems especially related to respiration in cities like Kathmandu. Although majority of the traffic police had knowledge that they need to use antipollution mask, fewer of them felt like going for regular health checkup. Regular checkups save lives even when there is no specific problem, since the absence of disagreeable symptoms does not necessarily guarantee that one is in good health. Some studies have also shown decreased rates of invasive cancers and decreased mortality in people who undergo regular medical checkup [16-18]. Therefore, awareness creating activities and policies relating to regular health checkup and protection from polluted environment should be launched effectively.

This study showed that the level of knowledge regarding the prevention of respiratory problems among the traffic police was comparatively higher than the level of practice. Similar results were obtained in a study done in India; the level of knowledge was found to be better in majority of traffic police while the level of practice was average [19]. This might be due to financial problems faced by the traffic police as studies have suggested that socioeconomic factors play a role in the health seeking behaviors. In addition, lack of time management during duty periods could prevent attending regular health checkup $[20,21]$. Nonetheless, they should be motivated to have healthy and safe practice against the pollution. Furthermore, the government should draft sustainable policies addressing such issues.

The majority of traffic police used masks to prevent respiratory problems in this study. A study revealed that the use of facial masks could help to reduce the negative effects of air pollution [22]. A minority of the traffic police implemented rules in vehicles for less emission of gases in this study. This might be due to ineffective rules regarding prevention of vehicular emission. In Kathmandu Valley, vehicular emission is the major contributor to air pollution [9]. A study done in Kathmandu Valley showed that the total estimated emission $\left(\mathrm{CO}, \mathrm{CO}_{2}, \mathrm{HC}, \mathrm{NO}_{\mathrm{X}}, \mathrm{SO}_{2}\right.$, and $\mathrm{PM}_{10}$ ) was 7,231,053.12 tons/year, the majority of which was $\mathrm{CO}_{2}$ (91.0\%) and CO (5.0\%) [6]. In addition, at the time of this study, demolition of buildings and construction of roads were in progress. This could have aggravated the condition of air, eventually deteriorating the health of the traffic police. The good health of traffic police and city dwellers is ensured only if the government implements vehicle inspection and emission testing effectively and ban on polluting vehicles.

The present study showed that education affected the level of knowledge in prevention of respiratory problems among traffic police. However, there was no association between education and level of practice to prevent respiratory problems. The poor practice of the traffic police, despite better knowledge, has not been fully understood necessitating further research in this regard. This study also showed that working experience had association with the level of practice but not with the level of knowledge. A research work suggests that, with longer experience, people increase their level of performance [23]. It is better to learn preventive measures against air pollution from experience and practice them in daily life.

This study was not without limitations. First, all traffic stations in Kathmandu Metropolis could not be taken into account due to budget limitation. Second, it would have been better to observe the practices of the traffic police rather than to provide them with the questionnaires to fill them.

In the future, research can be done by providing some interventions like training to the traffic police and observing the outcome in their knowledge and practice. Other health effects such as hearing impairment, eye problems, 
TABLE 5: Association of experience with level of knowledge and practice on prevention of respiratory problems.

\begin{tabular}{|c|c|c|c|c|c|c|c|c|}
\hline \multirow{2}{*}{ Experience (in years) } & \multicolumn{4}{|c|}{ Level of knowledge } & \multicolumn{4}{|c|}{ Level of practice } \\
\hline & $\mathrm{I}(\%)$ & II (\%) & III (\%) & $P$ value & $\mathrm{I}(\%)$ & II (\%) & III (\%) & $P$ value \\
\hline $1-5(n=18)$ & $6(33.3)$ & $7(38.9)$ & $5(27.8)$ & \multirow{4}{*}{0.33} & $15(83.3)$ & $1(5.6)$ & $2(11.1)$ & \multirow{4}{*}{0.04} \\
\hline $6-10(n=46)$ & $12(26.1)$ & $21(45.6)$ & $13(28.3)$ & & $42(91.3)$ & $3(6.5)$ & $1(2.2)$ & \\
\hline $11-15(n=17)$ & $2(11.8)$ & $5(29.4)$ & $10(58.8)$ & & $15(88.2)$ & $2(11.8)$ & $0(0.0)$ & \\
\hline $16-20(n=2)$ & $0(0.0)$ & $1(50.0)$ & $1(50.0)$ & & $1(50.0)$ & $0(0.0)$ & $1(50.0)$ & \\
\hline
\end{tabular}

Note. I: below average; II: average; III: above average.

hypertension, and respiratory functions can be studied among the traffic police.

\section{Conclusion}

More than ninety percent of the traffic police mentioned that difficulty in breathing was a major sign and symptom when they get respiratory problems. Among the ways, the use of mask and regular health checkup can prevent the effects of air pollution. The majority of the traffic police used masks during duty hours and had rotation in duty areas in order to prevent respiratory problems. The level of knowledge among the traffic police is adequate, but the level of practice on prevention of respiratory health problems is not satisfactory. Association of level of practice was observed with working experience but not with education of the traffic police in Kathmandu. It is the responsibility of the government and concerned authorities to deal with the issues and derive effective and sustainable solutions to ensure better health of traffic police in the city.

\section{Conflict of Interests}

The authors declare that they do not have any conflict of interests regarding the publication of this paper.

\section{Acknowledgments}

The authors appreciate the support of the Metropolitan Traffic Police Division, Kathmandu, and the traffic police who participated in this study. Similarly, the authors acknowledge the faculties of Maharajgunj Nursing Campus, Tribhuvan University, for their guidance and suggestions in conducting this study. The authors would also like to thank Leslie Melnyk, B.S., Crop Science and Management, University of California, Davis, for proof editing.

\section{References}

[1] S. T. Ingle, B. G. Pachpande, N. D. Wagh, V. S. Patel, and S. B. Attarde, "Exposure to vehicular pollution and respiratory impairment of traffic policemen in Jalgaon city, India," Industrial Health, vol. 43, no. 4, pp. 656-662, 2005.

[2] S. Gupta, S. Mittal, A. Kumar, and K. D. Singh, "Respiratory effects of air pollutants among nonsmoking traffic policemen of Patiala, India," Lung India, vol. 28, no. 4, pp. 253-257, 2011.
[3] Department of Transport Management Nepal Government, Details of Registration of Transport up to Fiscal Year 2046/47070/71, Department of Transport Management Nepal Government, Kathmandu, Nepal, 2014, http://www.dotm.gov .np/uploads/files/transport_registration_fiscal_year_2046_47_to_ 070_71_in_bagmati.pdf.

[4] S. Sangroula, Public Vehicles Hold Key to Better Transport Management in Capital, Kathmandu, 2014, http://www.myrepublica.com/portal/index.php?action=news_details\&news_id=67157.

[5] S. Udas, Public Transport Quality Survey, Clean Air Network Nepal/Clean Energy Nepal, Kathmandu, Nepal, 2012.

[6] K. P. Ghimire and S. R. Shrestha, "Estimating vehicular emission in Kathmandu Valley, Nepal," International Journal of Environment, vol. 3, no. 4, pp. 133-146, 2014.

[7] S. R. Yadav, V. K. Murthy, D. Mishra, and B. Baral, "Estimation of petrol and diesel adulteration with kerosene and assessment of usefulness of selected automobile fuel quality test parameters," International Journal of Environmental Science \& Technology, vol. 1, no. 4, pp. 253-255, 2005.

[8] C. Gautam, Action Plan for Air Quality Management in Kathmandu Valley, Ministry of Environment, Science and Technology, Government of Nepal, Kathmandu, Nepal, 2006.

[9] Clean Air Network Nepal/Clean Energy Nepal, Air Quality Status and Management in Kathmandu Valley: Make the City Air Breathable, Clean Air Network Nepal/Clean Energy Nepal, Kathmandu, Nepal, 2014.

[10] Ambient (Outdoor) Air Pollution in Cities Database by Country and City, World Health Organization, Geneva, Switzerland, 2014, http://www.who.int/phe/health_topics/outdoorair/databases/cities/en/.

[11] World Health Organization, Ambient (Outdoor) Air Quality and Health, World Health Organization, Geneva, Switzerland, 2014, http://www.who.int/mediacentre/factsheets/fs313/en/.

[12] L. van Bree and F. R. Casse, Toxicity of Ambient Air PM10: A Critical Review of Potentially Causative PM Properties and Mechanisms Associated with Health Effects, National Institute of Public Health and Environment, Bilthoven, The Netherlands, 2000.

[13] Nepal Health Research Council and World Health Organization, Development of Procedures and Assessment of Environmental Burden of Disease of Local Levels due to Major Environmental Risk Factors, Nepal Health Research Council, Kathmandu, Nepal, 2006.

[14] S. L. Shrestha, "Particulate air pollution and daily mortality in Kathmandu Valley, Nepal: associations and distributed lag," The Open Atmospheric Science Journal, vol. 6, supplement 1, pp. 6270, 2012.

[15] R. Sayyad, P. K. Yadav, M. Sekhar, A. Aliyaraj, and S. K. Kar, "Evaluation of pulmonary function tests on non smoking traffic 
police men at Tirupati, AP, India," International Journal of Physiotherapy and Research, vol. 1, no. 5, pp. 279-282, 2013.

[16] J. Ringash, "Preventive health care, 2001 update: screening mammography among women aged $40-49$ years at average risk of breast cancer," Canadian Medical Association Journal, vol. 164, no. 4, pp. 469-476, 2001.

[17] W. Berg, C. Linder, G. Eschholz, and J. Schubert, "Pilot study of the practical relevance of a one-step test for prostate-specific antigen in capillary blood to improve the acceptance rate in the early detection program of prostate carcinoma," International Urology and Nephrology, vol. 32, no. 3, pp. 381-388, 2001.

[18] C.-J. Chiou and H.-Y. Chang, "Do the elderly benefit from annual physical examination? An example from Kaohsiung City, Taiwan," Preventive Medicine, vol. 35, no. 3, pp. 264-270, 2002.

[19] G. S. Shashidhara, A descriptive study to assess the knowledge, attitude and practice regarding safety measure among traffic policemen, to protect against health hazards generated by traffic air pollution in Bangalore city [Ph.D. dissertation], Rajiv Gandi University of Health Sciences, Community Health Nursing, Bangalore, India, 2005.

[20] J. Chuma, L. Gilson, and C. Molyneux, "Treatment-seeking behaviour, cost burdens and coping strategies among rural and urban households in Coastal Kenya: an equity analysis," Tropical Medicine and International Health, vol. 12, no. 5, pp. 673-686, 2007.

[21] D. Adhikari and D. P. Rijal, "Factors affecting health seeking behavior of senior citizens of Dharan," Journal of Nobel Medical College, vol. 3, no. 5, pp. 50-57, 2014.

[22] J. P. Langrish, X. Li, S. Wang et al., "Reducing personal exposure to particulate air pollution improves cardiovascular health in patients with coronary heart disease," Environmental Health Perspectives, vol. 120, no. 3, pp. 367-372, 2012.

[23] K. A. Ericsson, "The influence of experience and deliberate practice on the development of superior expert performance," in The Cambridge Handbook of Expertise and Expert Performance, K. A. Ericsson, N. Charness, P. J. Feltovich, and R. R. Hoffman, Eds., pp. 685-706, Cambridge University Press, Cambridge, UK, 2006. 


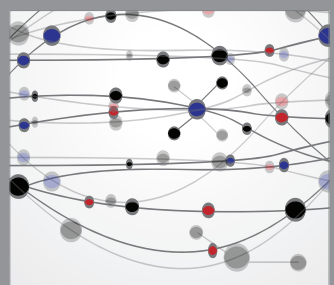

The Scientific World Journal
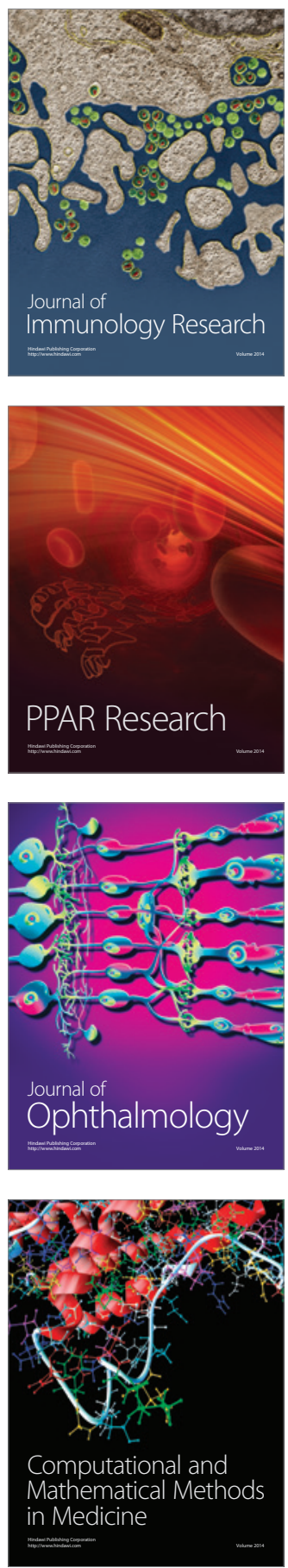

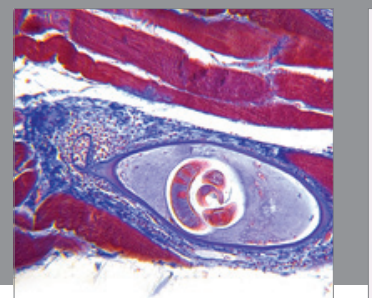

Gastroenterology

Research and Practice
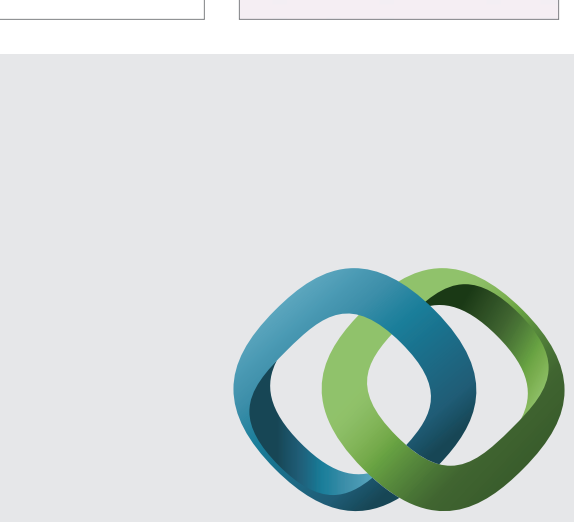

\section{Hindawi}

Submit your manuscripts at

http://www.hindawi.com
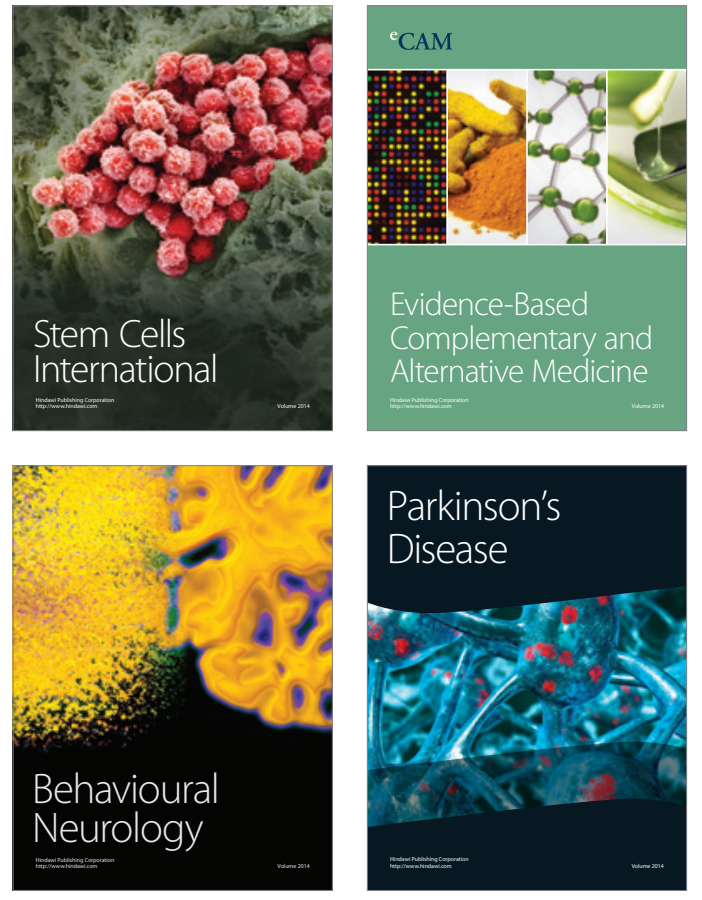
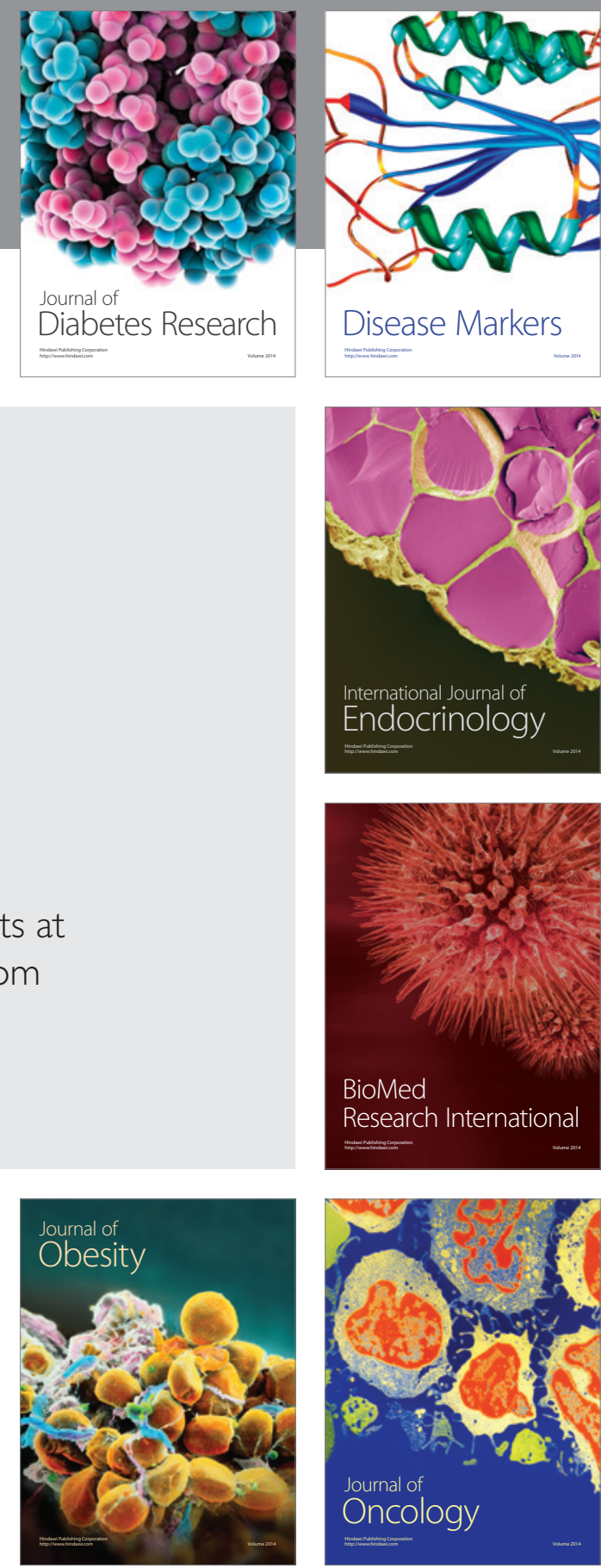

Disease Markers
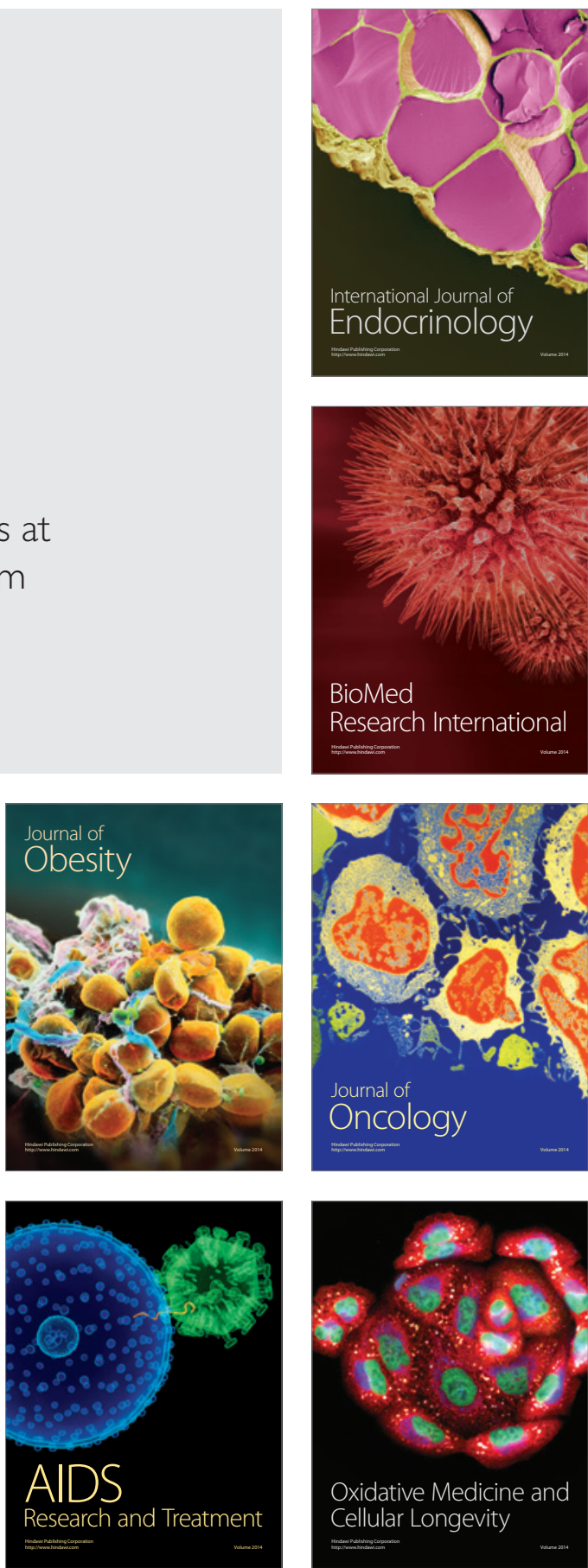